\title{
A DISCIPLINA DE PRÁTICA ENQUANTO COMPONENTE CURRICULAR IV E AS POTENCIALIDADES DE UMA FEIRA DE CIÊNCIAS
}

\author{
THE DISCIPLINE OF PRACTICE AS A CURRICULUM COMPONENT IV AND THE POTENCIALS \\ OF A SCIENCE FAIR
}

Adriele Prestes da Silveira (iD)

Instituto Federal Farroupilha, Júlio de Castilhos, RS, Brasil, adrieleprestesdasilveira@gmail.com

Dieison Prestes da Silveira (iD

Universidade Federal do Paraná, Curitiba, PR, Brasil, dieisonprestes@gmail.com

Joice Aline Freiberg iD

Universidade Federal de Santa Maria, Santa Maria, RS, Brasil, joice.freiberg@iffarroupilha.edu.br

DOI: http://dx.doi.org/10.31512/missioneira.v31i1.187 Recebido em: 08/03/2020 Aceito em: 10/07/2020

\begin{abstract}
Resumo: As feiras de ciências oportunizam as trocas de saberes, vivências e ex-periências entre alunos e professores. Diante disso, o presente artigo tem por ob-jetivo relatar e analisar a importância das feiras de ciências, tanto para a formação inicial e continuada de professores, quanto para o ensino e aprendizagem dos alunos, atentando para o incentivo a pesquisa no campo das ciências. $\mathrm{O}$ trabalho foi realizado na Escola Estadual de Ensino Fundamental Tupanciretã - RS com alunos do sexto ano do ensino fundamental. A feira de ciências é um projeto da disciplina de Prática enquanto Componente Curricular - PeCC IV - Feira de Ciên-cias do Curso de Licenciatura em Ciências Biológicas do Instituto Federal Far-roupilha - Campus Júlio de Castilhos. A metodologia para este estudo consiste em uma pesquisa com abordagem qualitativa, cujo procedimento técnico adotado consiste em uma pesquisa-ação. Os encontros na escola foram uma vez na semana durante quatro meses. Foram 12 alunos que realizaram diferentes ativida-des de pesquisa. Pode-se dizer que ocorreu um momento de reflexão, orientação e participação durante os encontros, bem como no momento da feira. Foi possível observar a interação entre os alunos na elaboração das atividades, bem como o êxito na proposta da feira de ciências. Diante disso, pode-se dizer que as feiras de ciências são espaços de trocas de saberes, vivências e experiências, embasados na socialização de experimentos e materiais didáticos.
\end{abstract}

Palavras-chave: Saberes. Formação inicial. Experimentos.

Abstract: The science fairs provide opportunities for the exchange of knowledge, experiences and experiences between students and teachers. Given this, this ar-ticle aims to report and analyze the importance of science fairs, both for the initial and continuing education of teachers, and for the teaching and learning of stu-dents, focusing on encouraging research in the field of science. The work was carried out at the Tupanciretã State School of Elementary School - RS with sixth grade students. The science fair is a project of the discipline of Practice as a Cur-riculum Component IV - Science Fair of the Degree Course in Biological Sciences of the Federal Institute Farroupilha - Campus Júlio de Castilhos. The methodology for this study consists of a research with qualitative approach, whose technical procedure adopted consists of an action research. The 
meetings at the school were once a week for four months. There were 12 students who performed differ-ent research activities. It can be said that there was a moment of reflection, orien-tation and participation during the meetings, as well as at the time of the fair. It was possible to observe the interaction between the students in the elaboration of the activities, as well as the success in the proposal of the science fair. Given this, it can be said that science fairs are spaces for exchanging knowledge, experienc-es and experiences, based on the socialization of experiments and teaching ma-terials.

Keywords: Know. Initial formation. Experiments.

\section{Introdução}

As feiras de ciências oportunizam as trocas de conhecimentos entre alunos, professores e a comunidade em geral, auxiliando no desenvolvimento da autonomia investigativa, principalmente dos alunos. O professor, nesse contexto, se torna um mediador do conhecimento oportunizando ao aluno o desenvolvimento de valores e atitudes, como por exemplo, proatividade, a autonomia, perfazendo a busca por respostas a problemas de ordem social, ambiental, cultural e/ou econômica. No tocante da feira de ciências, os alunos socializam suas experiências e constroem uma bagagem de vivências, sendo-as indispensáveis para o processo formativo, bem como para o desenvolvimento de habilidades e competências socioeducacionais. Adicionalmente, as feiras de ciências visam o planejamento e execução de atividades para incentivar a pesquisa nas escolas com diferentes contextos sociais. Frente a isso, o aluno se torna um pesquisador sob a orientação de professores, potencializando as trocas de conhecimentos nos diferentes níveis de ensino.

Sabe-se que as aulas de ciências são, normalmente, cercadas de muita expectativa e interesse por parte dos alunos. Existe uma motivação natural por aulas que apresentam caráter diferenciado, sendo que o aluno se torna um sujeito ativo dentro do contexto escolar, portanto, as feiras de ciências consistem em um exemplo de momento de investigação, conhecimento e socialização de experimentos. Ainda, a partir de uma feira de ciências o processo interdisciplinar, no campo educacional, é executado, haja vista que, diferentes conhecimentos e saberes são socializados, sendo que os professores realizam o processo de mediação, visando a busca por respostas as problemáticas dos alunos.

Em contrapartida das aulas diferenciadas, existem os momentos tradicionais que são expressos basicamente por teorias, gerando desestimulo nos alunos, o que pode refletir na baixa aprendizagem dos mesmos. Por isso, é importante que os professores de Ciências e Biologia, estejam dispostos a desenvolver aulas mais dinâmicas e que instiguem nos alunos o pensamento crítico-reflexivo, estimulando e preparando-os para o universo da pesquisa e, dessa forma, atentando para a aprendizagem. 
Na contemporaneidade, é importante compreender que as práticas diárias, principalmente no contexto educacional, precisam de intensas pesquisas, visto que, novas formas de mediar o conhecimento e incentivar as pesquisas, acabam surgindo. Frente a isso, o professor acaba sendo um pesquisador de sua própria prática docente, portanto, as instituições de ensino precisam divulgar as ações didático-pedagógicas, contribuindo com a qualidade do ensino, da pesquisa e da extensão.

No Instituto Federal Farroupilha do Campus Júlio de Castilhos há o curso de Licenciatura em Ciências Biológicas que auxilia na formação de educadores por meio de disciplinas, bem como projetos de ensino, pesquisa e extensão. Enfatizando as disciplinas, cabe destacar as Práticas enquanto Componentes Curriculares - PeCC's, as quais oportunizam ao professor em formação inicial, atividades que elencam o ensino, a pesquisa e a extensão. Diante disso, a PeCC IV que tem por incumbência a criação de uma Feira de Ciências em diferentes contextos e espaços educacionais, pauta o incentivo a sustentação científica dos alunos, possibilitando vivências aos professores em formação inicial, bem como novas aprendizagens no campo da educação.

Diante da necessidade de socializar vivências e experiências do cotidiano docente, o presente artigo tem o objetivo de relatar e analisar a importância das feiras de ciências, tanto para a formação inicial e continuada de professores, quanto para o ensino e aprendizagem dos alunos, atentando para o incentivo a pesquisa no campo das ciências.

\section{Desenvolvimento}

Definindo pesquisa, Fachin (2003, p. 3) comenta que "Pesquisa é um procedimento intelectual em que o pesquisador tem como objetivo adquirir conhecimentos por meio da investigação de uma realidade e da busca de novas verdades sobre um fato (objeto, problema)". A presente pesquisa do ponto de vista de sua abordagem classifica-se como pesquisa qualitativa. De acordo com Creswell (2010, p. 209), “A pesquisa qualitativa é uma forma de investigação interpretativa em que os pesquisadores fazem uma interpretação do que enxergam, ouvem e entendem". Ainda, sobre a importância das pesquisas qualitativas, Minayo (2012) comenta que no campo das ciências sociais as pesquisas qualitativas permitem um estudo aprofundado da realidade, permitindo ao pesquisador a obtenção de dados significativos.

Para este estudo, cabe salientar que foram utilizados referenciais bibliográficos como teses, dissertações, monografias e artigos científicos que abordam a temática feira de ciências e permitem um estudo aprofundado da relevância destas práticas em sala de aula. Sobre o uso de pesquisas bibliográficas, Ruiz (2002, p. 57) afirma que "Qualquer espécie de pesquisa, em qualquer área, supõe e exige pesquisa bibliográfica prévia, quer à maneira de atividade 
exploratória, quer para o estabelecimento do status quaestionis, quer para justificar os objetivos e contribuições da própria pesquisa".

Quanto aos procedimentos técnicos adotados para esta pesquisa podem-se dizer que foi utilizado uma pesquisa-ação, haja vista que, a cada encontro com os alunos-participantes, novas formas de pensar e agir para/com a feira de ciências eram vivenciadas, permitindo uma reflexão constante sobre a ação. Sobre pesquisa-ação, Thiollent (2011) comenta que por meio da pesquisa-ação o pesquisador se torna um sujeito flexível. Ainda, os participantes da pesquisa se tornam sujeitos ativos, pois podem dialogar com o pesquisador, visando uma construção significativa de conhecimentos.

Destaca-se que no mês de agosto do ano de 2019 iniciaram as atividades com os alunos do sexto ano da Escola Estadual de Ensino Fundamental Tupanciretã. Esta instituição educacional encontra-se localizada na cidade de Tupanciretã, no estado do Rio Grande do Sul. O primeiro encontro com os alunos teve por objetivo informá-los sobre as atividades de pesquisa para a feira de ciências que os mesmos deveriam realizar e, ainda, foi explanado a relevância de uma feira de ciências com vistas a construção de novos conhecimentos e saberes. Neste mesmo encontro foi salientado aos alunos do sexto ano que a temática da feira seria os conteúdos de ciências que o professor da disciplina estava trabalhando, tendo o intuito de contribuir diretamente com a disciplina de ciências e ampliar os conhecimentos dos alunos.

As atividades aconteceram durante quatro meses, sendo que durante este período, os alunos tiveram momentos de orientações, planejamentos, bem como a construção de materiais e experimentos para a feira de ciências. Destaca-se que os encontros ocorrem as quartas-feiras a tarde, visando auxiliá-los, bem como orientá-los no contra turno. Os alunos desenvolveram experimentos e materiais sobre: fungos, cadeia alimentar, germinação do feijão, bem como construíram um sementário.

\section{Resultados e discussão}

Em dezembro do ano de 2019 foi realizado o encontro na escola para a realização da feira de ciências, a qual contou com a participação dos alunos da escola. Também estavam presentes professores, gestores e a comunidade escolar, as quais puderam questionar os alunos e conhecer a importância de uma feira de ciências para a qualidade do ensino e para a autonomia dos alunos.

As Feiras de Ciências são eventos sociais, científicos e culturais realizados nas escolas ou na comunidade com a intenção de, durante a apresentação dos estudantes, oportunizar um diálogo com os visitantes, constituindo-se na oportunidade de discussão sobre os conhecimentos, metodologias de pesquisa e criatividade dos alunos em todos os aspectos referentes à exibição de trabalhos (BRASIL, 2006, p. 20). 
Adriele Prestes da Silveira | Dieison Prestes da Silveira | Joice Aline Freiberg

Participaram da feira de ciências doze alunos, com a construção de materiais sobre os fungos presentes no cotidiano, abordando o processo de decomposição dos alimentos por meio da confecção de cartazes. Ainda, teve experimentos de química, com um vulcão, cartazes sobre a cadeia alimentar, bem como a construção de um sementário, permitindo a catalogação de sementes de diferentes espécies vegetais.

$\mathrm{O}$ incentivo a pesquisa pelos alunos reflete diretamente no processo de ensino e aprendizagem, pois os alunos criam o hábito de buscar o conhecimento em diferentes locais, como por exemplo, livros, revistas e isso, possibilita aprendizagens diversas. Para o processo formativo de um docente, pode-se afirmar que o mesmo adquire habilidades que são necessárias para a atuação em sala de aula, visto que cada aluno apresenta suas vivências e experiências e o professor precisa ser um mediador do conhecimento.

A postura do professor em sala de aula, bem como suas artimanhas em articular o conteúdo teórico a ser ensinado com atividades mais dinâmicas e uma abordagem moderna são, sem dúvida pontos de partida para a solução de problemas em sala de aula, tanto no sentido disciplinar (comportamento do aluno) quanto no índice de rendimento de conteúdos que serão aproveitados pelo estudante (KUBATA et al., 2011, p. 2).

Foi possível observar que, para diferentes contextos educacionais, as feiras de ciências nas escolas apresentam-se como uma importante ferramenta educacional para o processo de ensino e aprendizagem, uma vez que ocorre o processo de interdisciplinaridade no campo do ensino, com as trocas de informações entre os alunos e as contribuições de outros docentes. Fazenda (2012, p. 8) comenta que a "interdisciplinaridade não se ensina, nem se aprende, apenas vive-se exerce-se e, por isso, exige uma nova pedagogia, a da comunicação.

As feiras de ciências são uma possibilidade de mediação de conhecimentos por meio do desenvolvimento de pesquisas. Tanto os alunos quanto os professores aprendem. Isso vem ao encontro do que Freire (1996) comenta, pois, o aluno precisa ter a autonomia de buscar o conhecimento e o professor, nesse contexto, se torna um mediador, orientando e sanando dúvidas. A feira de ciências teve esse intuito, de orientar e instigar o pensamento críticoreflexivo dos alunos, oportunizando a autonomia no campo investigativo da pesquisa na disciplina de ciências.

Para a formação inicial de professores a PeCC IV - Feira de Ciências, sendo um componente curricular obrigatório do curso de Licenciatura em Ciências Biológicas do Instituto Federal Farroupilha, estimula ao acadêmico vivências singulares possibilitando a construção de aprendizagens sobre a profissão docente e ainda, possibilita o desenvolvimento da autonomia do acadêmico no tocante do planejamento e execução de atividades com alunos.

Para o futuro profissional docente, ter experiências reflete diretamente na qualidade da educação, visto que cada sujeito apresenta seus saberes. Conforme relata Santos (2010), a ecologia de saberes consiste na diversidade de vivências e experiências e, se tratando do 
ambiente educacional, a formação de professores precisa atentar a polissemia de saberes, permitindo uma melhora no ensino e na aprendizagem educacional, portanto, as feiras de ciências perfazem as trocas de saberes e a socialização de vivências, sendo-as fundamentais para a contemporaneidade.

\section{Considerações finais}

As atividades da feira de ciências na Escola Estadual de Ensino Fundamental Tupanciretã foram de extrema relevância para o incentivo a pesquisa dos alunos, bem como para o exercício da docência. Diante disso, pode-se afirmar que por meio de uma feira de ciências, aprendizagens de caráter significativo acabam sendo desenvolvidas, o que proporciona a troca de saberes e informações, construindo assim, um ambiente de aprendizagens.

Durante as atividades da feira de ciências foi possível observar que os alunos estavam participativos e demostrando interação no tocante da explanação das atividades para a comunidade escolar. Isso mostra que os alunos se empenharam na elaboração das atividades, corroborando com as prerrogativas da feira de ciências.

Além de possibilitar a pesquisa no campo de ciências, as feiras nas escolas são uma forma de interação entre professor e aluno, visto que o professor se torna mediador do conhecimento atendando para os desejos e anseios das pesquisas dos alunos.

Para a formação de professores, as feiras de ciências são uma oportunidade de qualificar o acadêmico de licenciatura para a futura profissão enquanto educador, visando uma formação diferenciada com o desenvolvimento de habilidades e competências que são essenciais para o atual contexto educacional.

\section{Referências}

BRASIL. Ministério da Educação. Secretaria de Educação Básica. Programa Nacional de Apoio às Feiras de Ciências da Educação Básica Fenaceb. Brasília, DF, 2006.

CRESWELL, J. W. Projeto de pesquisa. Porto Alegre: Artmed, 2010.

FACHIN, O. Fundamentos de metodologia. 4. ed. São Paulo: Saraiva, 2003.

FAZENDA I. C. A. O que é interdisciplinaridade? 2. ed. São Paulo: Cortez, 2012.

FREIRE, P. Pedagogia da autonomia: saberes necessários à prática educativa. 25. ed. São Paulo: Paz e Terra, 1996. 
KUBATA, L., FRÓES, R. C.; FONTANEZI, R. M. M.; BERNABÉ, F. H. L. A postura do professor em sala de aula: atitudes que promovem bons comportamentos e alto rendimento educacional. Revista eletrônica de Letras, p. 1-26, 2011.

MINAYO, M. C. de S. (Org.). Pesquisa social: teoria, método e criatividade. 32. ed. Petrópolis, RJ: Vozes, 2012.

RUIZ, J. A. Metodologia científica: guia para eficiência nos estudos. São Paulo: Atlas, 2002.

SANTOS, B. S. A gramática do tempo: para uma nova cultura política. 3. ed. São Paulo: Cortez, 2010.

THIOLLENT, M. Metodologia da pesquisa-ação. 18. ed. São Paulo: Cortez, 2011. 